\title{
DETERMINAÇÃO OU DETERMINANTES SOCIAIS DA SAÚDE: TEXTO E CONTEXTO NA AMÉRICA LATINA
}

\author{
SOCIAL DETERMINATION OR SOCIAL DETERMINANTS OF \\ HEALTH: TEXT AND CONTEXT IN LATIN AMERICA
}

\author{
DETERMINACIÓN O DETERMINANTES SOCIALES DE LA SALUD: \\ TEXTO Y CONTEXTO EN AMÉRICA LATINA
}

\author{
Carolina Michelin Sanches de Oliveira Borghi ${ }^{1}$ \\ Rosely Magalhães de Oliveira ${ }^{2}$ \\ Gil Sevalho ${ }^{3}$
}

Resumo Determinação social da saúde e determinantes sociais da saúde têm se apresentado como sinônimos em um contexto de retomada do tema. A concepção de determinação e determinantes e a historicidade desses modelos teóricos transcende o plano acadêmico, ao se considerar a particularidade envolvendo saúde pública, saúde coletiva e medicina social, em que ciência e política se relacionam estreitamente. Ao se delinearem diferenças entre essas denominações, procura-se neste ensaio recuperar, no plano teórico, a elaboração de determinação social da saúde, destacando sua relação com o conhecimento produzido na América Latina e sua repercussão no Brasil, bem como as influências dos paradigmas científicos, epistemológicos, arcabouços teóricos e projetos em disputa nesse campo. Para abranger dimensões políticas e acadêmicas que os modelos teóricos comportam, recorremos ao auxílio de autores que transitam entre diferentes campos de conhecimento. Sem a pretensão de esgotar todos os possíveis pontos de contemplação que nossa incursão proporcionou, apresentamos uma síntese de nossa concepção do modelo teórico de determinantes sociais da saúde e sobretudo de determinação social da saúde, que propomos desmembrar em duas categorias, determinação estrutural e determinação estrutural-relacional, para, ao enfatizar epistemologicamente a complexidade, permitir melhor contemplação de avanços teóricos e metodológicos.

Palavras-chave determinação social da saúde; saúde coletiva; epidemiologia; epistemologia.
Abstract The social determination of health and the social determinants of health have been presented as synonyms in a context in which this topic is being revisited. The conception of determination and determinants and the historicity of these theoretical models transcend the academic realm, once we consider the particularity involving public health, collective health, and social medicine, in which science and politics have a close relationship. Through the description of the differences between these two terms, our aim in this essay was to bring back, in theory, the elaboration of the social determination of health, highlighting its relationship with the knowledge produced in Latin America and its repercussions in Brazil, as well as the influences of the scientific and epistemological paradigms, the set of theories, and the projects that are in dispute in this field. In order to encompass the academic and political dimensions contained in the theoretical models, we sought the help of authors that move among different fields of knowledge. Without the intention of covering all of the points of observation that our incursion provided, we present a summary of our conception of the theoretical model of the social determinants of health and, chiefly, of the social determination of health, which we suggest should be divided into two categories, structural determination and structural-relational determination, in order to enable a better observation of the theoretical and methodological improvements, by emphasizing complexity epistemologically.

Keywords social determination of health; collective health; epidemiology; epistemology.

(cc) BY Este é um artigo publicado em acesso aberto sob uma licença Creative Commons. 


\section{Introdução}

Desde que se intensifica a discussão sobre determinação/determinantes sociais da saúde, impulsionada pela incorporação do tema na agenda da Organização Mundial da Saúde (OMS) e de comissões nacionais, a incansável repetição dessas expressões pode ser esvaziada de sentido se não há clareza do conteúdo e implicações dos termos. Afinal, o que é determinação social do processo saúde-doença? E determinantes sociais da saúde? São denominações diferentes de um mesmo conceito? Abrigam-se conceitos distintos sob uma mesma denominação?

Entendemos o saber em saúde pública, saúde coletiva e medicina social envolvendo conhecimentos delineados nem sempre como campo único, já que se diferenciam em construção histórica e projetos, embora tenhamos feito a opção neste ensaio por reunir na expressão saúde coletiva/medicina social a produção de conhecimento da América Latina e do Brasil. É na centralidade desse contexto que observamos que o debate sobre determinação/ determinantes sociais da saúde tem se anunciado com aura de inovação. Um olhar atento, entretanto, percebe que autores latino-americanos já vinham se dedicando ao assunto há algumas décadas.

Cabe acentuar que se o tema é apreendido ao se refletir sobre sua concepção teórica, entendemos que a importância do debate se inscreve na agenda atual quando, no contexto mundial, avançam as propostas de gestão neoliberal, política e econômica. Interessa-nos enfatizar essa perspectiva da ordenação política ao referenciar a opinião de Harvey (2008) de que o neoliberalismo se tornou, mais do que projeto econômico, um tipo de cultura que afeta o pensar e o modo de se viver.

Com a intenção de recuperar contribuições e atualizar a discussão sobre o tema da determinação social da saúde, pretende-se no texto aqui apresentado realizar uma abordagem crítica - uma perspectiva cuja pertinência é defendida por Breilh (2011), ao sustentar que:

El disenso actual sobre los llamados 'determinantes sociales de la salud' pasa a ser uno de esos terrenos de oposición, donde se pugna por definir el campo de la salud colectiva; su contenido y su práctica. Para contrastar las perspectivas divergentes sobre determinación social de la salud, para comprender por qué la reflexión de grupos de salud colectiva se adelantó en tres décadas a la Organización Mundial de la Salud (OMS); para entender el debate actual de dicha categoría y los motivos por los cuales el pensamiento anglosajón invisibilizó la producción latinoamericana al lanzar al mundo su modelo, es necesario insertar dichas reflexiones en el movimiento de las relaciones sociales que batallan por constituir la práctica de la salud (Breilh, 2011, p. 29). 
Num primeiro momento, procura-se retomar a trajetória da saúde coletiva e da medicina social na América Latina, destacando suas contribuições acadêmicas, para em seguida apresentar os aspectos teóricos e conceituais que atravessam o tema determinação/determinantes sociais da saúde, com o intuito de delimitar suas diferenças, tradições epidemiológicas a que se filiam e suas respectivas propostas teóricas e políticas.

Enfatize-se a realização deste texto com um ensaio, construído sobre a leitura de bibliografia selecionada por sua representação para o desenvolvimento da reflexão. Ensaio é forma que Moisés (2004) apresenta como texto crítico que, por explorar o novo, não pretende comprovações e se constrói no correr da reflexão. Adorno (2003) ressalta que, mais que registro e classificação, o ensaio é interpretação; é texto que se coloca contra o menosprezo da história, rejeita a certeza e busca as contradições em que se enredam os conceitos, procurando revelar que a pretensa objetividade pode ser mero arranjo subjetivo.

\section{Trajetória da saúde coletiva/medicina social na América Latina e suas contribuições}

Sabroza (2005) descreve como a concepção de saúde e doença e os modelos teóricos que buscam sua compreensão se relacionam e entrelaçam com a organização social e seu respectivo acúmulo tecnológico em cada momento. $\mathrm{O}$ autor assinala a permanência e a coexistência de modelos antigos que ainda atendem a necessidades atuais, mantendo relações do passado com o presente.

Sintetizamos no Quadro 1 a classificação de modelos teóricos de explicação do processo saúde-doença proposta por Arredondo, que, embora elaborada em 1992, guarda sua atualidade.

\section{Quadro 1}

\begin{tabular}{|llll|}
\hline Modelos teóricos de explicação do processo saúde-doença, de acordo com Arredondo (1992) \\
\hline Modelo & $\begin{array}{l}\text { Aspectos teóricos/ } \\
\text { variáveis }\end{array}$ & Época & Principais autores \\
\hline Modelo Mágico-Religioso & $\begin{array}{l}\text { Forças, espíritos, castigo } \\
\text { divino } \\
\text { Condiçōes insalubres } \\
\text { (sociais) } \\
\text { Condiçōes de vida e de } \\
\text { trabalho }\end{array}$ & $\begin{array}{l}\text { Sociedades primitivas até a } \\
\text { atualidade } \\
\text { Revolução industrial européia }\end{array}$ & $\begin{array}{l}\text { Sem autores no campo } \\
\text { científico } \\
\text { Smith e Pettenkofer }\end{array}$ \\
Modelo Social & $\begin{array}{l}\text { Agentes externos } \\
\text { Agente, hospedeiro e }\end{array}$ & Século XIX-XX & Década de 1950 \\
Modelo Multicausal & $\begin{array}{l}\text { Rembiente } \\
\text { Rede de causalidade- } \\
\text { fatores de risco }\end{array}$ & Década de 1960 & Prank, Virchow e Ramazzini \\
\hline
\end{tabular}




\begin{tabular}{|c|c|c|c|}
\hline \multicolumn{4}{|c|}{ Modelos teóricos de explicação do processo saúde-doença, de acordo com Arredondo (1992) } \\
\hline Modelo Ecológico & $\begin{array}{l}\text { Agente, hospedeiro e } \\
\text { ambiente e relações } \\
\text { entre eles }\end{array}$ & Década de 1970 & Susser \\
\hline Modelo Histórico-Social & $\begin{array}{l}\text { Contexto social, modo } \\
\text { de produção, classe } \\
\text { social }\end{array}$ & Década de 1970 & Berlinguer, Laurell e Breilh \\
\hline Modelo Geográfico & $\begin{array}{l}\text { Interação entre fatores } \\
\text { patológicos e fatores } \\
\text { próprios do ambiente } \\
\text { geográfico }\end{array}$ & Década de 1950 & Jaques May e Voronov \\
\hline Modelo Econômico & $\begin{array}{l}\text { Renda, padrão de } \\
\text { consumo, estilo de vida, } \\
\text { nível educacional, riscos } \\
\text { ocupacionais }\end{array}$ & Décadas de 1970 e 1980 & Anne Mills, Gilson e Muskin \\
\hline Modelo Interdisciplinar & $\begin{array}{l}\text { Hierarquizados, } \\
\text { diferentes níveis de } \\
\text { determinação }\end{array}$ & Década de 1990 & Frenk \\
\hline
\end{tabular}

Fonte: Elaborado com base em Arredondo (1992).

Ao examinar as permanências e rupturas entre modelos teóricos do processo saúde-doença, de meados do século XIX até a atualidade, Arredondo (1992) aponta que a transição de um modelo para outro se processou de modo a incorporar novas variáveis, mas sem conflitos aparentes intermodelos, por meio de um 'jogo científico' dirigido à manutenção do status quo. $\mathrm{O}$ autor faz uma ressalva ao afirmar que somente os modelos mágico-religioso e históricosocial expressam elementos que destoam dos demais.

Arredondo (1992) caracteriza o modelo histórico-social como aquele que busca explicar perfis diferenciados de saúde e doença por intermédio de uma estreita relação com o contexto histórico, o modo de produção e as classes sociais. Afirma que esse modelo traz como novas variáveis de análise a dimensão histórica, a classe social, o desgaste laboral do indivíduo e a reprodução da força de trabalho.

O modelo histórico-social reveste-se de especial importância, uma vez que seus elementos de ruptura em relação aos demais permitiram o avanço teórico em direção à construção do conceito de determinação social do processo saúde-doença. Ainda que não exista consenso na literatura, especialmente se comparamos produções em diferentes idiomas, chamamos de determinação social do processo saúde-doença o constructo acadêmico herdeiro do modelo histórico-social e que se apropria de suas categorias-chave, e de determinantes sociais da saúde as concepções que derivam dos outros modelos teóricos.

Para se entender como o modelo histórico-social se desenvolveu em nossa região, América Latina e Brasil, é preciso recapitular o desenrolar de nosso campo de conhecimento. Ao descreverem o percurso da saúde pública e da saúde coletiva/medicina social na América Latina, López-Arellano e Saint Martin (2006) identificam três momentos para sua caracterização, relacionados com o desenvolvimento histórico e econômico. Um primeiro momento, recor- 
tado de forma bastante ampla e chamado pelas autoras de fase de expansão capitalista, estende-se da colonização até após a Segunda Guerra Mundial, quando a economia latino-americana se baseava na exploração de recursos naturais para exportação. Nessa época, uma inconclusa formação dos estados nacionais, somada à marcada ingerência dos centros importadores, resultava em ações de saúde pública voltadas para o controle e a erradicação de doenças infecciosas, com o protagonismo de organismos dos segundos e a anuência dos primeiros. A motivação dessas ações residia em interesses econômicos, uma vez que epidemias representavam ameaças para as trocas comerciais. Uma plataforma preventivista, alicerçada no modelo epidemiológico unicausal, dialogava não só com o andamento científico epidemiológico, mas também com a organização do Estado naquele período.

A segunda fase, de substituição de importações, segundo López-Arellano e Saint Martin (2006), delimita-se entre as décadas de 1940 e 1980. As pesquisadoras assinalam o desenvolvimento dos estados nacionais da região nessa época, com a incipiente responsabilização deles para a elaboração e execução de ações de saúde pública e assistência, com pretensões de garantir a reprodução da força de trabalho. Nesse recorte temporal, em que paralelamente aos primórdios da industrialização aceleraram-se a urbanização, o êxodo rural e a incorporação das mulheres ao mercado de trabalho, têm-se no plano epidemiológico o acréscimo das doenças crônico-degenerativas às ainda prevalentes infectocontagiosas e, no plano acadêmico, a emergência dos modelos ecológicos multicausais, que buscam apreender essa nova situação. As autoras situam nesse período, sobre o qual impactam teorias dependentistas e projetos neoliberais, a origem do pensamento latino-americano em saúde, que floresce a partir da década de 1980 e representa a última e atual fase do percurso da medicina social latino-americana.

Iriart e colaboradores (2002) dedicam-se a entender o contexto do desenvolvimento da medicina social latino-americana e, ao fazê-lo, apontam que seu surgimento se deu em meio a uma situação de crise do que denominam de 'saúde pública desenvolvimentista', quando se constata o equívoco da ideia de que o crescimento econômico da região levaria ao desenvolvimento, pois as condições de vida e saúde se agravaram. Os autores destacam que, desde seu nascimento, o pensamento latino-americano em saúde caracterizou-se por seu compromisso com a transformação das condições concretas do viver, pela percepção das relações entre estrutura social e problemas de saúde e pela aliança entre grupos acadêmicos e movimentos sociais.

O pensamento latino-americano em saúde, que se organizou de forma a engendrar o que se conhece como saúde coletiva no Brasil e medicina social no restante da América Latina, veio, de acordo com Iriart e colaboradores (2002), a configurar um rompimento epistemológico e de práxis em relação à saúde pública no tocante à compreensão de seus objetos e propósitos. A própria 
adoção do nome saúde coletiva reflete que saúde "es un proceso construido colectivamente, tanto en la forma que adquiere en cada sociedad y momento histórico como en las posibilidades de transformarlo" (Iriart et al., p. 128).

Em artigo voltado para a difusão das contribuições latino-americanas para leitores de língua inglesa, Waitzkin e colaboradores (2001) aprofundam-se na descrição das condições de surgimento, sobrevivência, aportes teóricos e metodológicos dos principais grupos de pesquisa afins aos fundamentos da medicina social. Os pesquisadores extraem as principais colaborações de grupos situados na Argentina, no Brasil, Chile, Colômbia, Cuba, Equador e México, sintetizadas no Quadro 2.

Quadro 2

\begin{tabular}{|c|c|c|c|}
\hline \multicolumn{4}{|c|}{ Grupos latino-americanos de medicina social: contextos e contribuições } \\
\hline País & Grupos acadêmicos & $\begin{array}{l}\text { Contexto sociopolítico e } \\
\text { acadêmico }\end{array}$ & Contribuições \\
\hline Argentina & Buenos Aires, Rosário, Córdoba & $\begin{array}{l}\text { Com o golpe de1976, pesquisadores } \\
\text { enfrentam desemprego e exílio. } \\
\text { Depois de 1983, dificuldades de } \\
\text { reintegração e complementam } \\
\text { atividades de investigação com } \\
\text { outros empregos. Grupos próximos a } \\
\text { movimentos sociais. }\end{array}$ & $\begin{array}{l}\text { Papel dos atores sociais, } \\
\text { saúde mental, saúde } \\
\text { ambiental, relações entre } \\
\text { o perfil epidemiológico e a } \\
\text { estrutura de classes, pobreza } \\
\text { e marginalização }\end{array}$ \\
\hline Brasil & $\begin{array}{l}\text { Universidade de São Paulo } \\
\text { (USP), Universidade Estadual de } \\
\text { Campinas (Unicamp), Fundação } \\
\text { Oswaldo Cruz (Fiocruz), Instituto } \\
\text { de Medicina Social (IMS), } \\
\text { Universidade Federal da Bahia } \\
\text { (UFBA) }\end{array}$ & $\begin{array}{l}\text { A maioria dos investigadores se } \\
\text { mantém no país durante a ditatura. } \\
\text { Fontes regulares de financiamento. } \\
\text { Reforma sanitária, implementação de } \\
\text { um sistema universal de saúde. }\end{array}$ & $\begin{array}{l}\text { Papel e repercussão da } \\
\text { medicina preventiva, } \\
\text { processo de trabalho, } \\
\text { participação popular, } \\
\text { epidemiologia crítica, } \\
\text { determinação social }\end{array}$ \\
\hline Chile & $\begin{array}{l}\text { Santiago } \\
\text { Grupo de Investigación y } \\
\text { Capacitación en Medicina Social } \\
\text { (GICAMS) }\end{array}$ & $\begin{array}{l}\text { Interrupção dos trabalhos com o } \\
\text { golpe militar e escassa reintegração } \\
\text { com a transição democrática. Grupos } \\
\text { associados a organizações não } \\
\text { governamentais }\end{array}$ & $\begin{array}{l}\text { Saúde mental e efeitos } \\
\text { da repressão, saúde do } \\
\text { trabalhador, gênero e saúde, } \\
\text { privatização da saúde }\end{array}$ \\
\hline Colômbia & Bogotá, Medellín, Cali & $\begin{array}{l}\text { Situação de violência, exílio de } \\
\text { investigadores, assassinato de } \\
\text { professores, reformas neoliberais } \\
\text { radicais }\end{array}$ & $\begin{array}{l}\text { Doenças infecciosas, } \\
\text { investigações de base } \\
\text { comunitária, classes sociais e } \\
\text { saúde, violência e saúde }\end{array}$ \\
\hline Cuba & $\begin{array}{l}\text { Escuela Nacional de Salud Pública } \\
\text { (ENSAP) }\end{array}$ & $\begin{array}{l}\text { Avanços alcançados pela Revolução, } \\
\text { estabilidade para investigação }\end{array}$ & $\begin{array}{l}\text { Atenção primária, } \\
\text { envelhecimento e doenças } \\
\text { crônicas, doenças infecciosas, } \\
\text { saúde mental e ambiental }\end{array}$ \\
\hline Equador & $\begin{array}{l}\text { Quito, Centro de Estudios y } \\
\text { Acesoria en Salud (CEAS) }\end{array}$ & $\begin{array}{l}\text { Aproximação de lutas políticas e } \\
\text { contra a privatização, próximo a } \\
\text { movimentos populares }\end{array}$ & $\begin{array}{l}\text { Epidemiologia social e } \\
\text { contribuições teóricas e } \\
\text { metodológicas }\end{array}$ \\
\hline México & $\begin{array}{l}\text { Ciudad de México } \\
\text { Universidade Autónoma de } \\
\text { Metropolitana- Xochimilco } \\
\text { (UAM-X), Guadalajara }\end{array}$ & $\begin{array}{l}\text { Regularidade de suporte público, } \\
\text { grupos em ambientes universitários, } \\
\text { participação em movimentos } \\
\text { populares e partidários }\end{array}$ & $\begin{array}{l}\text { Políticas de saúde, } \\
\text { acordos internacionais, } \\
\text { desenvolvimento econômico } \\
\text { e saúde, contextos sociais, } \\
\text { privatização, saúde indígena }\end{array}$ \\
\hline
\end{tabular}

Fonte: Elaborado com base em Waitzkin e colaboradores (2001). 
Ao discorrer sobre o percurso da medicina social latino-americana, Laurell (2011) frisa a importância de uma recapitulação histórica para a compreensão de sua atualidade e tendências. A pesquisadora divide essa trajetória em três períodos e associa a produção de cada fase ao respectivo contexto sociopolítico, alertando para a sobreposição desses períodos e para o fato de que eles não se processaram sincronicamente nos distintos países.

Um primeiro instante, ainda segundo Laurell (2011), estaria delimitado entre fins da década de 1970 e os últimos anos da década seguinte. A próxima etapa teria início no final da década de 1980 e se estenderia até os anos 1990, quando começaria a fase em que ainda nos encontramos. No Quadro 3, sistematizamos os principais pontos de cada fase, com seus respectivos contextos, contribuições teóricas e metodológicas e desafios.

\begin{tabular}{|c|c|c|c|}
\hline \multicolumn{4}{|c|}{ Trajetória da medicina social latino-americana: contextos, temas, contribuições e desafios } \\
\hline $\begin{array}{l}\text { A fundação e o clímax } \\
\text { das lutas populares }\end{array}$ & $\begin{array}{l}\text { Oposição à 'saúde pública } \\
\text { desenvolvimentista', } \\
\text { regimes ditatoriais em } \\
\text { vários países, urbanização } \\
\text { e industrialização, } \\
\text { estabelecimento dos grupos } \\
\text { pioneiros }\end{array}$ & $\begin{array}{l}\text { Determinação Social do } \\
\text { Processo Saúde-doença, } \\
\text { materialismo dialético, crítica } \\
\text { ao causalismo, epidemiologia } \\
\text { crítica, nexo biopsicossocial, } \\
\text { incorporação de ciências } \\
\text { sociais }\end{array}$ & Alto grau de abstração \\
\hline $\begin{array}{l}\text { A democratizaçãoe as } \\
\text { reformas de saúde }\end{array}$ & $\begin{array}{l}\text { Paradoxo: democratização } \\
\text { e neoliberalismo, tarefa } \\
\text { legislativa }\end{array}$ & $\begin{array}{l}\text { Participação e controle } \\
\text { social, pobreza versus } \\
\text { desigualdade, críticas } \\
\text { teóricas e empíricas } \\
\text { às reformas e discurso } \\
\text { neoliberal, questões } \\
\text { ambientais e de gênero }\end{array}$ & $\begin{array}{l}\text { Apropriação do } \\
\text { discurso progressista } \\
\text { pelo neoliberalismo, } \\
\text { ocupação dos espaços } \\
\text { versus denúncia e } \\
\text { oposição, aliança crítica } \\
\text { com a Saúde Pública } \\
\text { tradicional, maior } \\
\text { visibilidade e penetração }\end{array}$ \\
\hline $\begin{array}{l}\text { O pós-liberalismo } \\
\text { e as emergências } \\
\text { progressistas }\end{array}$ & $\begin{array}{l}\text { Evidências de falhas das } \\
\text { reformas neoliberais, } \\
\text { emergência de governos } \\
\text { progressistas }\end{array}$ & Categorias "de moda" & $\begin{array}{l}\text { Vigilância epistemológica } \\
\text { e cooptação de } \\
\text { terminologia }\end{array}$ \\
\hline
\end{tabular}

Fonte: Elaborado com base em Laurell (2011).

No Brasil, pode-se entender que a cooptação de termos se revela também pela influência neoliberal, no desgaste das políticas públicas setoriais que se originaram na perspectiva crítica da Reforma Sanitária, quando se percebem contradições entre o discurso oficial progressista e práticas gestoras conservadoras.

Indica-se, então, por que Laurell (2011) ressalta a importância da incorporação de uma vigilância epistemológica na atualidade, uma vez que as categorias originalmente trazidas pela medicina social latino-americana, ao serem integradas ao discurso hegemônico, adulteram seu significado. Espe- 
cial atenção deve ser dada à discussão da determinação social da saúde e aos avanços produzidos sobre o tema na região (Iriart et al., 2002).

Acercar-se dos modelos teóricos de determinação/determinantes sociais da saúde exige que nos ocupemos de diferentes eixos que os atravessam. A formulação teórica de determinação/determinantes acompanha e reflete a própria construção do campo da saúde pública e da saúde coletiva/medicina social, razão pela qual, em um primeiro momento, atentamos para o esboço desse campo, suas relações de autonomia e heteronomia, suas concepções e projetos em disputa, paradigmas científicos e referenciais teóricos. Posteriormente, trouxemos contribuições de autores que vêm se dedicando à discussão sobre determinação/determinantes sociais da saúde, de modo a delimitar modelos teóricos e explorar divergências. Por fim, apresentamos nossa concepção desses modelos.

\section{Saúde pública e saúde coletiva/medicina social como campo científico}

Almeida-Filho e Paim (1999) recuperam os pressupostos básicos que estruturaram o ensino, a investigação e a extensão na saúde coletiva brasileira:

La salud, en tanto estado vital, sector de producción y campo de saber, está articulada a la estructura de la sociedad a través de sus instancias económica y políticoideológica, poseyendo, por lo tanto, una historicidad (Almeida-Filho e Paim, 1999, p. 15).

Para entender o contexto de influências apresentado pelos autores citados em sua referência ao nosso campo de conhecimento, recorremos a Bourdieu (2003), que se dedica, em Os usos sociais da ciência: por uma sociologia clínica do campo científico, à análise da produção de instituições científicas. Ele identifica duas tradições de interpretação das produções: a científica, que denomina de internalistas ou internas; e externalistas ou externas. Delineia a primeira tradição como aquela que procura a compreensão das produções por meio de seus produtos, o que chama de 'a letra do texto'. Já a segunda é caracterizada por uma tentativa de relacionar os produtos com o mundo social ou econômico, ou 'o texto ao contexto'.

Ao apontar as debilidades de ambas as abordagens, Bourdieu (2003) defende o uso da noção de campo, sendo este o mediador entre os contextos gerais e a produção em si. Campo é conceituado pelo autor como "o universo no qual estão inseridos os agentes e as instituições que produzem, reproduzem ou difundem a arte, a literatura ou a ciência. Esse universo é um mundo social como os outros, mas que obedece a leis sociais mais ou menos específicas" (Bourdieu, 2003, p. 20). 
López-Arellano (2013), ao refletir sobre as insuficiências da saúde coletiva/ medicina social na atualidade, destaca a delimitação imprecisa de seu campo - o que se deveria, segundo a autora, a fragilidades de ordem teórica e metodológica. Almeida-Filho e Paim (1999), por sua vez, concluem que ainda que a saúde coletiva não possa ser apresentada como um novo paradigma científico, ela vem se consolidando como campo científico e âmbito de práticas.

Ponderamos que sua origem de ruptura epistemológica, de objeto e de projeto com a saúde pública, colocaria a saúde coletiva/medicina social como um campo próprio e, ao mesmo tempo, em disputa com a saúde pública, compartilhando espaços institucionais, de produção científica ou de intervenção política.

Bourdieu (2003) reconhece o campo científico como um campo de forças e um campo de lutas. Se recuperamos a noção da díade ciência-política, que molda a construção da saúde pública e da saúde coletiva/medicina social, vemos que as duas espécies de capital científico trazidas por Bourdieu revestem-se de especial complexidade no conhecimento em discussão. Segundo o autor, a primeira espécie, o capital científico 'puro', deriva do reconhecimento e do prestígio adquirido por meio de contribuições aos avanços e inovações na ciência. Por sua vez, o capital científico institucionalizado relaciona-se com a ocupação de posições que outorgam poder sobre os meios de produção e reprodução.

Para Bourdieu (2003), os campos, como sistemas complexos - por serem suscetíveis às pressões a eles exteriores e, simultaneamente, por pautarem-se por leis próprias de seus microcosmos -, são dotados da capacidade de refratar essas pressões segundo seus graus de autonomia. Campos com elevada autonomia conseguiriam retraduzir pressões ou demandas externas de acordo com suas leis ou princípios, transfigurando-as. O autor afirma que, "inversamente, a heteronomia de um campo manifesta-se, essencialmente, pelo fato de que os problemas exteriores, especialmente os problemas políticos, aí se exprimem diretamente" (Bourdieu, 2003, p. 22).

Sujeitos à heteronomia, os campos da saúde pública e da saúde coletiva/medicina social e, consequentemente, suas produções científicas são influenciados pelos contextos sociopolítico e acadêmico. Breilh (2010), à semelhança de Bourdieu, sublinha que são as relações de poder - e não só as diferenças éticas ou técnicas - que forjam os dissensos científicos nessa área. Assim, alerta para a "politicidad interna implícita del conocimiento" (Breilh, 2010, p. 119).

O mesmo Breilh (2010) identifica pressões que recaem sobre a investigação em saúde, percebendo que os pesquisadores, por meio de seu modo de vida e relações sociais, são a materialização do elo entre as mediações econômicas, institucionais e culturais e a produção científica em si. 


\section{Concepções e projetos em disputa no campo da saúde pública e da saúde coletiva/medicina social}

Conceber a saúde pública e a saúde coletiva/medicina social como campos particularizados por sua sensibilidade à heteronomia proporciona um caminho para o entendimento de concepções e projetos que aí se enfrentam. A essência da relação entre projetos e produção passa pelas categorias que permitem o conhecimento do mundo social, sendo esta uma luta política e, simultaneamente, teórica e prática (Bourdieu, 1989).

Ao refutar a tese da neutralidade do conhecimento, Barbosa (2010) se vale da noção de imperialismo simbólico de Bourdieu para analisar a infiltração dos preceitos neoliberais no campo da saúde coletiva. A supressão de conceitos, ou o silêncio sobre eles, serviria para torná-los invisíveis e, portanto, excluir problemáticas da discussão teórica e também política. Outro mecanismo de penetração, segundo a autora, seria a neutralização de conceitos, outrora críticos, pela cooptação e pelo enquadramento deles no marco discursivo neoliberal.

Sendo ao mesmo tempo contexto e projeto, o neoliberalismo contunde o conhecimento em saúde pública e saúde coletiva/medicina social de distintas formas. Atinge a esfera das ações em saúde pública e não deixa de fazê-lo no domínio da produção científica. Breilh (2000) assevera que uma luta emancipadora não prescinde de um posicionamento político e filosófico. Argumenta que informação é teoria em ato e, fundamentalmente, política em ato. E caracteriza, em linhas gerais, dois projetos em disputa na América Latina: por um lado, a captação privada dos espaços estatais; por outro, a luta dos coletivos pelos espaços solidários da sociedade.

\section{A saúde pública e a saúde coletiva/medicina social: paradigmas científicos}

Se destacamos a vinculação do fazer acadêmico a projetos políticos, em cada época e local, são necessárias reflexões sobre os paradigmas que direcionaram a construção científica nos últimos séculos e a sua pertinência, ou adequação, na atualidade.

Sem deixar de apontar os limites externos do paradigma dominante, representados pela insuficiência em atender às demandas trazidas pelos contextos sociopolítico e cultural, Santos (2006) observa fraquezas no contexto epistemológico e assinala que as convenções do paradigma dominante, positivista, já não condizem com o acúmulo científico, inclusive das ciências naturais. $\mathrm{O}$ autor caracteriza o paradigma dominante ressaltando a ascendência das ciências naturais sobre as sociais, a marcada separação entre ciência e senso comum, a pretensão de alcance da verdade e de controle da natureza, a defesa acrítica do rigor científico exercido por medições, a busca por leis e causalidades, e a redução da complexidade, dada por meio de divisões e classificações. Salienta 
que essas convenções originárias das ciências naturais, revestidas de aura de legitimidade, terminam por se transmitir às ciências sociais.

Ao tecer críticas ao paradigma dominante, como a suposição da neutralidade do conhecimento ou a artificialidade da disjunção entre sujeito e objeto, Santos (2006) atesta que sua crise é não apenas profunda, mas também irreversível. Em contraposição, qualifica o paradigma emergente como aquele que almeja, numa perspectiva interdisciplinar e complexa, a superação da distinção entre ciências sociais e naturais, não se direcionando a uma ciência unificada, mas a uma ciência que se reconheça como construção social, admitindo a incerteza, a inter-relação entre o conhecimento e o autoconhecimento e o diálogo com o senso comum.

Ao diferenciar os paradigmas dominante e emergente, Santos $(2006,2007)$ referencia o primeiro ao pressuposto de regulação e o segundo ao de emancipação na perspectiva das epistemologias do Sul (Santos e Meneses, 2010), que se contrapõem àquelas hegemônicas do Norte. É diante dessas questões de ordem epistemológica e crítica que deve se colocar a saúde coletiva/medicina social, erigindo-se sobre mais de uma disciplina, herdando conhecimentos advindos tanto das ciências naturais como das ciências sociais e trabalhando com eles.

Ao explorar a pertinência do debate epistemológico na epidemiologia, Samaja (1998), por sua vez, contextualiza a irrupção de correntes de contestação, o que leva à reaparição do que denomina de 'paradigma marginal' da modernidade, ou seja, o historicismo e a dialética. Conclui que sua principal vantagem consiste na possibilidade da inclusão da complexidade, prescindindo da forçosa separação entre os níveis individual ou social.

Almeida-Filho (2006) considera que a incorporação da perspectiva da complexidade no campo da saúde demanda uma reformulação tanto de objetos conceituais como da prática científica para se repensar e reconstruir o conhecimento.

Espina-Prieto (2007), ao abordar a complexidade, enuncia três perspectivas para a investigação social (Quadro 4). Nesta concepção, a aproximação e a inclusão do observador nos sistemas que se quer conhecer relacionam-se com o poder de controle sobre a investigação e sua pretensão, sendo a perspectiva mais complexa aquela de construção de ações socialmente transformadoras mediante a participação assumida do investigador na situação estudada. 


\begin{tabular}{|c|c|c|c|}
\hline \multicolumn{4}{|c|}{ Perspectivas metodológicas da investigação social } \\
\hline Perspectiva & Distributiva/ Quantitativa & Estrutural/ Qualitativa & Dialética/ Reflexiva \\
\hline Poder & Absoluto & Relativo & Reflexivo \\
\hline $\begin{array}{l}\text { Momento de } \\
\text { explicitação do poder }\end{array}$ & $\begin{array}{l}\text { Poder implícito: } \\
\text { o observador está fora do } \\
\text { sistema que observa e sobre } \\
\text { o qual atua e não leva em } \\
\text { consideração o que está fora }\end{array}$ & $\begin{array}{l}\text { Poder parcialmente } \\
\text { explicitado: o observador-ator } \\
\text { está fora e reconhece isto. } \\
\text { Admite a possibilidade de } \\
\text { muitos observadores, cada } \\
\text { qual com sua perspectiva }\end{array}$ & $\begin{array}{l}\text { O observador-ator reconhece } \\
\text { que está dentro do sistema que } \\
\text { observa e sobre o qual atua e se } \\
\text { reconhece como dispositivo de } \\
\text { autorreflexão do sistema }\end{array}$ \\
\hline $\begin{array}{l}\text { Relação com a } \\
\text { promoção de } \\
\text { mudanças }\end{array}$ & $\begin{array}{l}\text { Dispositivo de controle } \\
\text { Técnicas estabilizadoras }\end{array}$ & $\begin{array}{l}\text { Taticamente promotoras } \\
\text { Estrategicamente } \\
\text { estabilizadoras } \\
\text { Mudanças dentro de limites } \\
\text { externamente estabelecidos }\end{array}$ & Promoção de mudanças sociais \\
\hline Posição do sujeito & $\begin{array}{l}\text { Suposição de } \\
\text { objetividade Sujeito } \\
\text { como observador externo } \\
\text { Esvaziado }\end{array}$ & $\begin{array}{l}\text { Suposição de reflexividade } \\
\text { parcial Integrado parcial e } \\
\text { transitoriamente }\end{array}$ & $\begin{array}{l}\text { Reflexividade radical } \\
\text { Sujeito interior e em processo } \\
\text { integrado }\end{array}$ \\
\hline $\begin{array}{l}\text { Propósito do } \\
\text { conhecimento }\end{array}$ & Conhecer & Compreender & Transformar por dentro \\
\hline Espaço em que opera & Elementos do sistema & $\begin{array}{l}\text { Relações entre elementos } \\
\text { (estrutura) }\end{array}$ & $\begin{array}{l}\text { Relação entre as relações } \\
\text { Mudanças de estruturas } \\
\text { Sistemas dinâmicos }\end{array}$ \\
\hline
\end{tabular}

Fonte: Elaborado com base em Espina-Prieto (2007).

\section{Saúde pública e saúde coletiva/medicina social: referencial teórico}

O campo da saúde pública e da saúde coletiva/medicina social compõe-se da afluência de distintas disciplinas ou áreas do conhecimento e nele esgrimem paradigmas concorrentes. Se já aludimos à dupla ocupação, político-institucional e acadêmica, desse campo, cabe ainda destacar que seu ramo acadêmico comporta uma miríade de referenciais teóricos.

Ao analisarem os usos teórico-metodológicos correntes nas pesquisas daquilo que denominam de subcampo das ciências humanas e sociais em saúde, Deslandes e Iriart (2012) salientam tanto a grande variedade de perspectivas, oriundas de diferentes disciplinas, como a fragilidade do embasamento teórico em boa parte dos estudos por eles revisados, sugerindo um 'empirismo ateórico'. Apontam como possível explicação para seus achados uma deficiente formação teórico-metodológica dos autores, facultada pelas instituições de educação nessa área.

Barbosa (2010), ao recuperar a ideia de campo como espaço de lutas, reflete sobre o papel das teorias sociais nesse embate e sobre sua repercussão na produção acadêmica no campo da saúde. Do texto da autora depreendese que a preeminência de certas teorias sociais sobre outras, ou até mesmo a aparente ausência destas, relaciona-se intimamente com os contextos sociopolítico e acadêmico. Assim, ela afirma que o entendimento de como e por que se processou a neutralização do conhecimento crítico passa por "analisar as políticas científica e educacional que vêm regendo os processos de trabalho e a 
produção científica nas instituições públicas de ensino e pesquisa nas últimas décadas" (Barbosa, 2010, p. 12). Alerta também para as "relações obscuras entre recursos públicos e privados" para a ingerência de agências internacionais, que se perpetra por meio de linhas de financiamento.

Como destaca Barbosa (2010), o marxismo serviu de importante referência teórica no campo da saúde coletiva até fins da década de 1980. A autora faz uma ressalva nesse ponto, dizendo que outras perspectivas interpretativas do marxismo, calçadas no referencial dialético e relacional, sempre existiram, mesmo no campo contra-hegemônico. Segundo a pesquisadora, a partir da década seguinte e até nossos dias esse referencial teórico foi se esvanecendo do campo da saúde. Para ela, se esse fato se deveu a causas políticas reais e concretas, não deixou de ser reflexo do avanço do neoliberalismo.

A perda de instrumentos teóricos críticos abriu espaço para a profusão de teorias da pós-modernidade que, de acordo com Barbosa (2010, p. 11), “fragmentam a abordagem e o enfrentamento do capitalismo enquanto totalidade social, reduzindo a compreensão das relações sociais a práticas discursivas". Essas teorias são retratadas por Breilh (2010) como conservadoras, empenhadas em desconstruir relatos de emancipação.

\section{Determinação social do processo saúde-doença e determinantes sociais da saúde}

Após visitar a saúde pública e a saúde coletiva/medicina social na América Latina, sua trajetória, seus projetos em disputa, paradigmas e referenciais científicos e contextos sociais de produção, prosseguimos na consideração sobre determinação e determinantes sociais da saúde, procurando entender como os diversos aspectos da questão se condensam em modelos teóricos.

Ao examinar o documento de 2008 da OMS sobre determinantes sociais da saúde, Nogueira (2009) atenta para a carência de densidade teórica do relatório. Segundo ele, a OMS falha ao não definir determinantes sociais da saúde, remetendo vagamente a uma ideia de causa ou causalidade social. O autor avalia que o relatório assume 'social' como um fator a mais, e não como algo que englobe as dimensões biológica, ambiental e genética da vida e da saúde humanas. Assim, a saúde perde tanto seu caráter de processo como mais especificamente o de processo social, o que revela a concepção biomédica da saúde implícita no documento, que se presta a obscurecer os papéis da estrutura social e das condições de vida. Segundo Nogueira (2009), a fragilidade do relatório reside na ausência de uma teoria social que o respalde, apoiando-se somente na empiria, herança do positivismo, e deslizando para o determinismo.

O determinismo é ressaltado como traço fundamental da concepção de determinantes sociais da saúde da OMS também por López-Arellano, 
Escudero e Carmona (2008), Breilh (2010), Peñaranda e Rendón (2013) e Restrepo-Ochoa (2013). Todos estes autores localizam o determinismo presente na concepção da OMS como reflexo da adoção dos paradigmas científicos hegemônicos.

É importante, com base nas considerações apresentadas, abordar resumidamente reflexões sobre determinismo, indeterminismo, determinação e determinantes pelo prisma da filosofia para, então, apresentarmos como se enxergam as diferenças entre determinação e determinantes sociais da saúde e, finalmente, ofereceremos nossa concepção desses modelos teóricos.

Ao recorrermos a uma perspectiva histórica para entender como o determinismo veio a posicionar-se no cerne da ciência moderna, sintetizamos algumas das principais observações feitas por Peñaranda e Rendón (2013) ao explorarem filosoficamente a tensão determinismo/indeterminismo dos gregos até a atualidade.

Concentrados em esclarecer como sujeito e sua relação com a natureza, liberdade humana, causalidade e acaso foram representados na filosofia e na ciência em diferentes momentos históricos, Peñaranda e Rendón (2013) iniciam seu panorama com os filósofos pré-socráticos. Os autores identificam duas visões contrárias entre os pré-socráticos: a monista, na qual se propõe a unidade do ser e o pensar e se concebe a realidade como estática e determinada em todos os aspectos; e a pluralista, para a qual existem vários princípios e um universo em movimento.

Peñaranda e Rendón (2013) esclarecem que Platão, ao buscar uma margem de liberdade dentro do determinismo, aventa a dualidade tanto da realidade, entre física e das ideias, como do ser humano, entre um corpo mortal e uma alma imortal, bem como do conhecimento - entre verdadeiro, das ideias, episteme, e sensível, doxa, elaborado pelos sentidos. Aristóteles, por sua vez, lida com a questão ao sugerir a unidade de corpo e alma, sendo o primeiro, matéria, e a segunda, forma; e simultaneamente o determinismo do mundo físico em oposição à indeterminação da vontade, onde caberia a liberdade humana.

Se, ao analisarem a Idade Média, Peñaranda e Rendón (2013) apreendem o alcance do Cristianismo ao imprimir uma concepção determinista teológica, deslocando-se para a modernidade, os autores encontram nesse período as chaves que permitem conectar o desenvolvimento das ciências naturais, os paradigmas positivistas e o determinismo que ainda se infiltra nas concepções científicas atuais, inclusive no que tange aos determinantes sociais da saúde, como proposto pela OMS. A essência das premissas dos autores encontra-se no vínculo entre a busca de leis que permitam explicitar as causas que regem ou configuram o universo e a noção de que tais leis são as que terminam por determinar a realidade. O determinismo inerente a esse modelo científico, que se projeta para além das ciências naturais com a hegemonia do positi- 
vismo, é refutado, entre outros, por Hegel (Peñaranda e Rendón, 2013). Ao identificarmos a transcendência dos enunciados de Hegel para a formulação da determinação social da saúde, procuramos condensar a profundidade e a complexidade de seu pensamento em algumas poucas linhas, segundo Peñaranda e Rendón (2013).

Para estes autores, Hegel, expoente do idealismo alemão, vale-se da dialética para suplantar a causalidade em favor da mediação. Os princípios de que o desenvolvimento implica movimento, passando de um ser em potência para a expressão dessa potência, são o esteio das ideias de Hegel. Esta perspectiva abre espaço tanto para o enriquecimento da compreensão da relação entre o ser humano e a natureza como para a liberdade, por meio da relação do ser humano não só com a natureza, mas também consigo mesmo.

Percebe-se que Hegel, ao borrar o enquadramento positivista de causa e efeito, postula o processo de determinação por mediações intrínsecas, que se referem às potencialidades como características que conferem identidade ao ser, e extrínsecas, entre o ser e as determinações. Peñaranda e Rendón (2013) sintetizam esse pensamento da seguinte forma:

'Algo' se puede reconocer como aquello que preserva su identidad - o, en efecto, logra y establece su identidad en el proceso de ser y devenir en otro (Peñaranda e Rendón, 2013, p. 51).

Restrepo-Ochoa (2013) concebe a determinação como uma alternativa para a superação da tensão entre determinismo e indeterminismo. O autor destaca que se uma construção determinista da ciência, tal como no positivismo, enseja limitações, um ponto de vista que se inscreve por meio do indeterminismo, como trilhado pela física quântica, não deixa de fazê-lo. Indo ao encalço das implicações éticas e metodológicas das molduras científicas, em particular no campo da saúde, o autor frisa os entraves que uma concepção baseada no indeterminismo traz ao trabalhar com probabilidades e acaso, ou azar, desprovendo-se de capacidade explicativa e restringindo a liberdade humana. Ainda assim, reconhece as contribuições daqueles que se dedicaram às teorias da complexidade no intuito de superar esse impasse e buscar um entendimento da realidade que não a fragmentasse.

Ao abordar os fundamentos filosóficos de causa e determinação, Nogueira (2010) distingue quatro concepções de determinação:

(a) relação meramente empírica de causa e efeito, validada por métodos estatísticos;

(b) a lei universal que relaciona um evento a outro no tempo, como causa e efeito; 
(c) a especificação de um conceito de modo dialético e que origina o real como 'concreto pensado';

(d) o fundamento histórico da compreensão do ser dos entes enquanto physis, criatura ou objeto (Nogueira, 2010, p. 141).

Ao utilizar Kant, Hegel, Marx e Heidegger como interlocutores, Nogueira (2010) ressalta que o conceito de determinante não representa mais que um fator empírico causal.

Fleury-Teixeira (2009) concorda com Nogueira (2010), ao interpretar que a compreensão da determinação social da saúde requer a assimilação prévia tanto da determinação social dos indivíduos como do conceito de saúde com o qual se trabalha. Breilh (2010) amplia a questão, propondo que se trabalhe com a determinação social da vida, e não apenas da saúde. E Almeida-Filho (2010) apropria-se da teoria da determinação de Bunge para, no esforço de superar a ideia de causalidade, propor determinação como conceito geral, que poderia subdividir-se em determinação causal, dialética ou estrutural.

Breilh (2010) também se afilia à noção de determinação de Bunge e acrescenta que as bases epistemológicas da elaboração latino-americana da determinação social da saúde partiram da contestação do causalismo. A dialética é eixo fundamental para a apreensão da determinação social da saúde, como explicita o autor:

La salud humana y los ecosistemas son objetos que incluyen procesos de carácter biológico socialmente determinados. Cuando pensamos sobre dicha determinación social de la salud, si queremos cuidar una perspectiva dialéctica que no recaiga ni en el determinismo biológico ni en el determinismo histórico, tenemos que trabajar las relaciones 'social-biológico' y 'sociedad-naturaleza', de tal manera que ninguna de las partes pierda su presencia en la determinación (Breilh, 2010, p. 100).

Ao tensionar o tema mediante a crítica epistemológica e filosófica, percebemos, então, que com a denominação de determinação social do processo saúde-doença e determinantes sociais da saúde não se opõem apenas dois constructos distintos, mas sim um mosaico de concepções, com graus variados de convergência e divergência. Assim, estamos cientes de que, no esforço de agrupar esses conceitos, ganhamos instrumentos que podem vir a potencializar o debate, mas inevitavelmente perdemos na amplitude de proposições.

Também é importante que façamos uma ressalva quanto às denominações adotadas. Sabe-se que existem estudos que designam de determinantes sociais da saúde proposições que chamaremos de determinação social do processo 
saúde-doença. Reconhecemos, portanto, que autores possam discordar da nomenclatura assumida neste ensaio.

\section{Determinantes sociais da saúde}

Conceber o modelo de determinantes sociais da saúde como a amálgama de modelos teóricos do processo saúde-doença predecessores pode facilitar a apreciação de suas características e conformação. Com base nas reflexões de Sabroza (2005) e Arredondo (1992), afirmamos que o modelo de determinantes sociais da saúde representa uma tentativa de acomodar e modernizar, sem rupturas, a essência dos modelos ecológicos e suas variações.

Arredondo (1992) sustenta que as variáveis de análise em cada modelo são complementares e mantêm uma continuidade cronológica com os modelos anteriores, sendo que as diferenças residiriam no enfoque e no 'peso' atribuído a cada variável. O autor aponta que o fato de serem "cientificamente aceitáveis" conduz à estagnação da construção do conhecimento, ainda que não se questione a possibilidade de falsidade de seus enunciados hipotéticos (Arredondo, 1992, p. 259).

Breilh (2013), em texto em que procura relacionar as perspectivas na investigação sobre determinação/determinantes sociais da saúde e suas respectivas tradições epidemiológicas, situa a linha dos determinantes sociais da saúde dentro da epidemiologia tradicional, alcunhando esse enfoque como 'causal de transição'.

O modelo teórico de determinantes sociais de saúde, associado à orientação da OMS, é frequentemente referenciado à representação de Dahlgren e Whitehead (Buss e Pellegrini-Filho, 2007). A observação deste modelo nos conduz a alguns estranhamentos. Em primeiro lugar, percebe-se que sua centralidade não recai sobre coletividades, mas sim sobre indivíduos, destacando como suas únicas características idade, sexo (e não gênero) e fatores hereditários, sem menção à raça/etnia ou à maneira como essas particularidades transcendem a individualidade na medida em que são significadas de acordo com as experiências sociais. Nota-se também que 'estilo de vida dos indivíduos' aparece como determinante, sem que haja uma explanação clara de como ele se concatena com dimensões históricas e sociais. Uma última objeção diz respeito à ausência da nomeação da estrutura ou de classes sociais, mal substituídas por algo tão vago como 'condições socioeconômicas, culturais e ambientais gerais', 'condições de vida e de trabalho' e 'redes sociais e comunitárias'.

A OMS define determinantes sociais da saúde como "o conjunto das condições sociais nas quais os indivíduos vivem e trabalham" (Buss e PellegriniFilho, 2007, p. 78). Se esta conceituação não fala por si, é por meio daqueles 
que a criticam que podemos extrair sua essência, já registrando a extrema dificuldade em capturar o que se recusa a se revelar.

A respeito de seu embasamento teórico, Nogueira (2009) alerta que o relatório da OMS não se detém a definir o significado de determinantes sociais da saúde. E sobre suas relações paradigmáticas, científicas e históricas, o autor atesta seu marco teórico positivista, o determinismo social e o uso de fatores causais, próprio das ciências naturais e da epidemiologia tradicional.

Acerca da temporalidade e da centralidade adotadas pelo modelo de determinantes, López-Arellano, Escudero e Carmona (2008) destacam que a conversão de determinantes em fatores ofusca os processos sociais e históricos, assim como as formas de relação entre os homens e destes com a natureza, simplificação que facilita sua concepção como a livre eleição de estilos de vida.

Das intenções políticas do enfoque de determinantes sociais da saúde, López-Arellano, Escudero e Carmona (2008) vislumbram que não se problematiza que as desigualdades sociais e de saúde são o produto do capitalismo, isto é: existe um discurso que, transvestido de 'politicamente correto', não se abstém de defender a economia de mercado. Estabelece-se, desse modo, o arcabouço teórico, raramente explicitado, que ao servir de tapume diante das forças motrizes da organização e estrutura social sustenta intervenções pontuais, conservadoras e desarticuladas.

Ao sintetizar as observações sobre o modelo dos determinantes, podemos acrescentar que a proposta não considera a historicidade e, consequentemente, o caráter de processo em que se situam as questões sociais; e ao fragmentar contextos em fatores, impõe uma ordenação linear aos determinantes.

Solar e Irwin (2005), ao se referirem às aplicações político-institucionais, mas também filosóficas e éticas, desse enfoque simplificador, questionam se a Comissão Internacional sobre Determinantes Sociais da Saúde estaria disposta a colocar em xeque o paradigma liberal em si, confrontando o papel do mercado e dos estados.

Foi necessário, no percurso crítico traçado, abordarmos em seguida um modelo teórico que buscasse apreender as causas estruturais do processo saúde-doença.

\section{Determinação social do processo saúde-doença}

Optamos por desmembrar a determinação social do processo saúde-doença em duas categorias: determinação estrutural e determinação estrutural-relacional. Tomamos a liberdade de designá-las dessa maneira para enfatizar o eixo central da proposição de análise das relações entre o processo saúdedoença e sua determinação social. Esta nomenclatura, que sabemos não encontrar respaldo na literatura, inspirou-se livremente nas contribuições de Espina-Prieto (2007) no que tange ao estudo das perspectivas metodológicas 
da investigação social e complexidade. Tal divisão tem como intuito permitir melhor contemplação dos avanços teóricos e metodológicos sobre determinação social do processo saúde-doença, no sentido de superar, paulatina e progressivamente, suas insuficiências.

Vale reafirmar que o trabalho de Espina-Prieto (2007) aponta para relações entre complexidade, inclusão do investigador na situação em questão e ação socialmente transformadora sobre a realidade. Acentue-se, então, que compor com ideias de complexidade não implica necessariamente relacionar projeto científico com propósitos de transformação social, pelo que, se nos aproximamos da reflexão de Espina-Prieto, assumimos a perspectiva da realização de ciência socialmente crítica diante da realidade social e política.

Assim, se para o modelo de determinantes sociais da saúde alguns autores salientam, entre outras fragilidades, a omissão do papel da estrutura social no processo saúde-doença, na concepção que chamamos de determinação estrutural o eixo explicativo é deslocado do indivíduo para o contexto sociopolítico e para a estratificação social. Este marco teórico incorpora a reflexão de Arredondo (1992) em seu modelo histórico-social, notadamente quando são relacionados perfis de saúde com contextos sociais, modo de produção e classes sociais.

Nessa concepção conceitual, identificada como de determinação estrutural, é interessante também vislumbrar as considerações de Paim (1997), autor que podemos referenciar ao que caracterizamos como campo da saúde coletiva/ medicina social, quando discorre a respeito de categorias importantes para se pensarem sentidos da estratificação social em sua relação com a saúde:

A partir da estruturação das classes sociais nas diferentes etapas do desenvolvimento do capitalismo, os indivíduos se submetem a formas distintas de inserção na estrutura ocupacional disponível que conforma o mercado de trabalho (ou delas são excluídos), bem como a um dado modo de vida. Na medida em que os trabalhadores encontram postos nesse mercado, vendem sua força de trabalho em troca de um salário (ou remuneração) que influi no seu modo de vida. Este pode ser decomposto analiticamente em condições de vida, garantidas diretamente por seus rendimentos ou indiretamente através de políticas públicas que asseguram a distribuição dos bens de consumo coletivo, e em estilo de vida, enquanto conjunto de comportamentos, hábitos, atitudes, etc. O mercado de trabalho estabelece ainda as condições de trabalho (apesar da ação reguladora do Estado), às quais são subordinados os trabalhadores, capazes de gerar problemas de saúde. Relacionase com o processo de trabalho, enfim, o fato de que, na dependência do tipo, da intensidade, da insegurança, este produz acidentes e outras doenças ocupacionais. Por conseguinte, o perfil epidemiológico da população, enquanto componente da situação de saúde, é determinado, de um lado, pela estrutura de produção (in- 
serção na estrutura ocupacional), em especial, por meio do processo de trabalho e das condições de trabalho; de outro, pela estrutura do consumo (modo de vida) que, juntamente com a renda auferida no mercado de trabalho, conforma as condições e o estilo de vida (Paim, 1997, p. 10, grifos do autor).

No âmbito de uma epidemiologia social de raízes latino-americanas e transcendência no Brasil, a teorização elaborada por Breilh e Granda (1989) traça um 'perfil epidemiológico de classes', ao incorporar o modo de produção, a formação social, a reprodução social e as classes sociais como matrizes da determinação social do processo saúde-doença.

Apesar das potencialidades que a incorporação dessas categorias de análise aporta, Paim (1997) menciona que o teste de seus modelos teóricos em situações concretas foi tolhido por problemas conceituais e metodológicos não solucionados. Adverte que, em certos casos, estudos que buscaram apropriarse desses conceitos terminaram por justapor o referencial teórico marxista a métodos e técnicas comprometidos com a epidemiologia clássica.

Sobre as insuficiências de um modelo pensado dessa forma, Fleury-Teixeira e Bronzo (2010) pontuam que persistem lacunas no conhecimento dos nexos das determinações em microbiologia, micropsicologia e microssociologia.

Ao se aproximarem dessa impressão, atentando para o fato de que "no se ha resuelto suficientemente la trama teórico-metodológica" desse modelo, López-Arellano, Escudero e Carmona (2008, p. 331) identificam desafios na elaboração dos processos de articulação/subsunção entre o social, o ecológico e o psicobiológico nos limites das teorias sociais para compreender a relação entre indivíduo e sociedade e na assimilação da complexidade e da transdisciplinaridade.

A formulação do próximo modelo teórico, que chamamos de determinação estrutural-relacional, sistematiza os pontos que conquistariam a superação desses entraves para que se possa, como desejam Fleury-Teixeira e Bronzo (2010, p. 44), “encontrar uma determinação social da vida individual desde a produção material, mas não pelo determinismo monocausal e mecânico".

Ao conservar as conquistas do modelo anterior e manter a centralidade na sociedade, incorporando o contexto sociopolítico e a estrutura social, o modelo que chamamos de determinação estrutural-relacional transcende seu antecessor ao buscar revelar aspectos contidos na trama da estrutura social, ao procurar esmiuçar as mediações relacionais entre o contexto geral e o plano individual.

Na construção dessa última perspectiva, se já trouxemos a posição de Breilh (2010) sobre a importância da dialética para a determinação social do processo saúde-doença, falta tratarmos da subsunção por meio da qual se estabelece a inter-relação entre o social e o biológico. O autor a explica como 
(...) cambio permanente del patrón de transformaciones mutuas que se establece entre aquellos y el ambiente, pero en este cambio incide la determinación social; eso es lo que queremos decir al sostener que lo biológico se desarrolla bajo subsunción a lo social (Breilh, 2010, p. 101).

Na compreensão das relações entre o biológico e o social, comportando dimensões biopsicossociais, individuais e coletivas, o esquema apresentado na Figura 1, formulado por Sabroza (2005), integra-se ao que estamos chamando de determinação estrutural-relacional.

\section{Figura 1}

Níveis de organização e processos saúde-doença

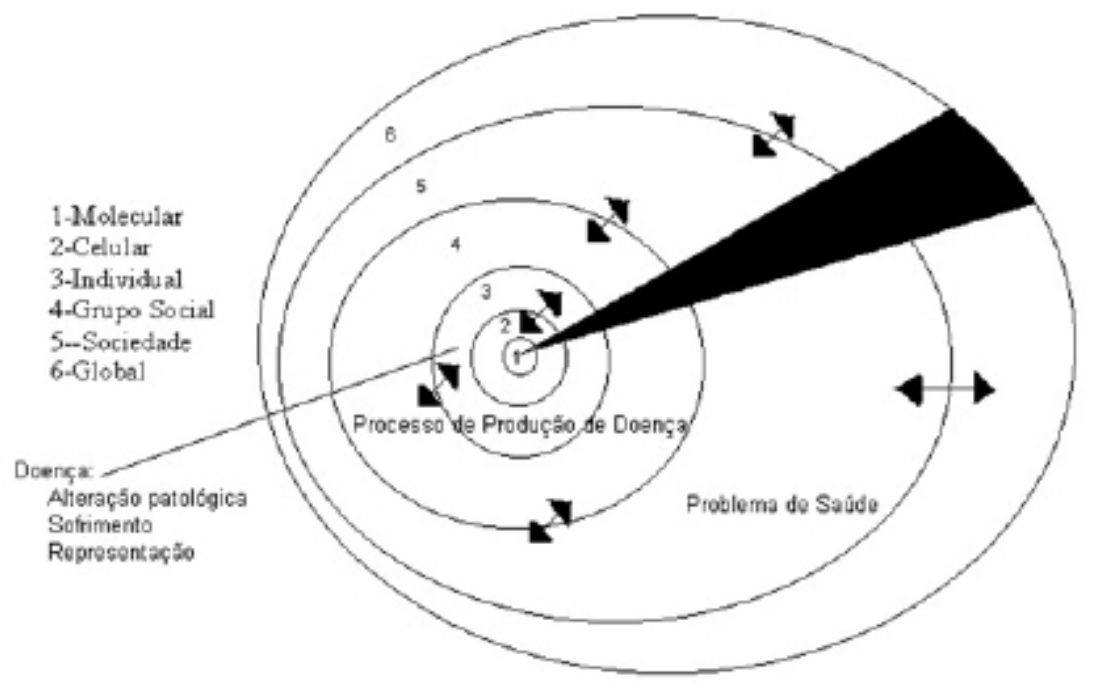

Fonte: Extraído de Sabroza (2005).

Sabroza (2005) busca a compreensão da produção social da doença e da saúde quando estabelece conexões, na complexidade do processo, incorporando à análise níveis de organização desde o molecular ao social e ao global e estabelecendo referências com o sofrimento e as representações de doença. Considerar o sofrimento e os modos de a população representar a saúde e a doença significa, em nosso entendimento, posicionar a determinação social na perspectiva que identificamos como estrutural-relacional.

Colabora para a compreensão que buscamos a reflexão que Breilh (2010) constrói ao evocar a ideia de Samaja quando este último incorpora a reprodução social na análise da determinação do processo saúde-doença. Samaja (2000, p. 74) retrata a reprodução social como processo com quatro dimen- 
sões: biológica (biocomunal), de autoconsciência e conduta (comunal-cultural), econômica (societal) e ecológico-política (estatal), em que "cada um desses quatro processos reprodutivos contém os outros como insumos ou condições de sua realização".

Castellanos (1997), ao interpretar a determinação de forma semelhante, enfatiza a diferença entre as perspectivas epidemiológicas de análise de doença e as de situação de saúde, remetendo esta última à expressão no nível individual e coletivo da reprodução social com seus quatro momentos: reprodução de processos predominantemente biológicos, processos ecológicos, formas de consciência e conduta e processos econômicos. Para Castellanos (1990), relações dialéticas entre os planos geral, particular e singular se desenvolvem por meio de processos de determinação e condicionamento.

Resta acrescentar que as relações de determinação, na concepção que denominamos determinação estrutural-relacional, constroem-se no nível da complexidade, para o que chama a atenção Castellanos (1997, p. 40), ao referir indivíduos e populações a uma "arquitetura da complexidade".

Reconhecemos que esse nível de compreensão da determinação social remete a aspectos e elementos de difícil apreensão em sua dimensão qualitativa e composição não linear, pelo que é útil a referência ao conhecimento produzido por Morin sobre complexidade. Para Morin (2011, p. 35), a complexidade em ciência "coincide com uma parte de incerteza" proveniente de nosso entendimento limitado ou "inscrita nos fenômenos" que estudamos e interpretamos - sendo, portanto, ligada a uma mistura "íntima" de ordem e desordem que constitui os sistemas naturais e sociais.

Nessa concepção, sujeito e objeto são indissociáveis e interagem em sistemas abertos segundo os princípios da complexidade definidos por Morin (2011, p. 73-74): o princípio "dialógico", que mantém a dualidade da ordem e da desordem no "seio da unidade"; o princípio da "recursão organizacional", segundo o qual produtos e efeitos "são ao mesmo tempo causas e produtores do que os produz"; o princípio "hologramático", que postula que a parte está no todo e o todo está na parte.

Se por um lado os três princípios da complexidade de Morin são interessantes para enriquecer a interpretação da determinação social do processo saúde-doença na perspectiva estrutural-relacional, por outro não nos afastamos da consideração das iniquidades sociais, sem a qual, em nome da abstração, nos distanciaríamos do compromisso de transformação social que queremos constituinte de nossa compreensão da questão.

Para Breilh (2006, p. 216), em uma leitura complexa desde sua epidemiologia crítica, escolher classe, gênero ou etnicidade como categorias de análise e conhecimento "da determinação da reprodução social e da saúde" tem a ver com o entendimento do "seu rico movimento e suas relações dialéticas como 
parte de uma estrutura de poder". O poder econômico concentra-se em distintas classes e se expressa numa determinada estrutura, "mas a dominação econômica requer relações culturais e uma estrutura simbólica adequadas, que viabilizem a hegemonia" (Breilh, 2006, p. 216).

O poder a ser revelado não é somente o que "controla a propriedade e o uso das riquezas materiais, mas também o poder que se requer para definir e expandir a identidade, os projetos e as aspirações de utopias" (Breilh, 2013, p. 8). Esse discernimento define, na compreensão da determinação social da saúde, uma prática científica de uma "epidemiologia sem memória e sem sonhos" (Breilh, 2006, p. 131) ou uma prática crítica socialmente comprometida com a justiça e a transformação do mundo.

Para esse modelo teórico, estrutural-relacional, confluem assim tanto os esforços no plano acadêmico, de absorver ideias provenientes da complexidade, da dialética e de teorias sociais engajadas, quanto, no plano político e institucional, os de melhorar não só as condições de saúde, mas também as de vida, em sentido amplo.

Mesmo reconhecendo que a formulação de diferentes categorias representa meramente um recurso acadêmico, que poderia não só restringir a riqueza do debate sobre a questão determinação/determinantes sociais da saúde como também ser injusta com diversos autores que, há mais tempo e com maior propriedade, vêm discorrendo sobre o tema, justificamos essa elaboração imbuídos do mais sincero desejo de contribuir para o avanço da reflexão sobre o tema. Nesse sentido, oferecemos no Quadro 5 a síntese de alguns pontos que julgamos primordiais na discussão.

É uma síntese explicativa do que entendemos como determinantes, determinação estrutural e estrutural-relacional. Com a apresentação esquemática, pretendemos resumir e esclarecer os pontos fundamentais de nossa proposta teórico-conceitual, ainda em construção. 
Quadro 5

\begin{tabular}{|c|c|c|c|}
\hline & $\begin{array}{l}\text { Determinantes sociais da } \\
\text { saúde como modelo teórico }\end{array}$ & $\begin{array}{l}\text { Determinação social estrutural } \\
\text { como modelo teórico }\end{array}$ & $\begin{array}{l}\text { Determinação social } \\
\text { estrutural-relacional } \\
\text { como modelo teórico }\end{array}$ \\
\hline $\begin{array}{l}\text { Contexto histórico } \\
\text { de elaboração }\end{array}$ & $\begin{array}{l}\text { A partir do pós segunda } \\
\text { guerra, perdurando até a } \\
\text { atualidade }\end{array}$ & $\begin{array}{l}\text { Ditaturas militares } \\
\text { Desenvolvimento dependentista } \\
\text { Neoliberalismo }\end{array}$ & $\begin{array}{l}\text { Contestação dos efeitos } \\
\text { da globalização e políticas } \\
\text { neoliberais }\end{array}$ \\
\hline $\begin{array}{l}\text { Relações } \\
\text { epistemológicas }\end{array}$ & $\begin{array}{l}\text { Saúde pública, clínica médica, } \\
\text { positivismo, epidemiologia } \\
\text { tradicional }\end{array}$ & $\begin{array}{l}\text { Saúde coletiva/ medicina social } \\
\text { latino-americana, medicina } \\
\text { comunitária, materialismo- } \\
\text { dialético, epidemiologia social } \\
\text { latino-americana }\end{array}$ & $\begin{array}{l}\text { Saúde coletiva/ medicina social } \\
\text { latino-americana, medicina } \\
\text { comunitária, materialismo- } \\
\text { dialético, epidemiologia crítica }\end{array}$ \\
\hline $\begin{array}{l}\text { Características da } \\
\text { população }\end{array}$ & $\begin{array}{l}\text { Somatória de indivíduos, } \\
\text { carece de estrutura ou relações } \\
\text { próprias }\end{array}$ & $\begin{array}{l}\text { Apresenta estrutura social, } \\
\text { moldada pelo contexto } \\
\text { econômico e sociopolítico }\end{array}$ & $\begin{array}{l}\text { Apresenta estrutura social, } \\
\text { moldada pelo contexto } \\
\text { econômico e sociopolítico e } \\
\text { relações biopsicossociais }\end{array}$ \\
\hline Relações sociais & $\begin{array}{l}\text { Inexistentes, fragmentação } \\
\text { em fatores }\end{array}$ & $\begin{array}{l}\text { Mediadas pela estrutura } \\
\text { econômica e social }\end{array}$ & $\begin{array}{l}\text { Mediadas pela estrutura } \\
\text { econômica e social } \\
\text { e suas inter-relações }\end{array}$ \\
\hline $\begin{array}{l}\text { Relação tempo- } \\
\text { espaço }\end{array}$ & $\begin{array}{l}\text { Estática e ahistórica } \\
\text { Espaço como ambiente } \\
\text { meramente físico }\end{array}$ & $\begin{array}{l}\text { Historicidade na produção da } \\
\text { estrutura social }\end{array}$ & $\begin{array}{l}\text { Historicidade na produção da } \\
\text { estrutura social e do território }\end{array}$ \\
\hline Enfoque científico & $\begin{array}{l}\text { Simplista } \\
\text { Enfoque disciplinar }\end{array}$ & $\begin{array}{l}\text { Busca a complexidade de } \\
\text { forma reducionista Enfoque } \\
\text { interdisciplinar }\end{array}$ & $\begin{array}{l}\text { Complexidade } \\
\text { Enfoque transdisciplinar }\end{array}$ \\
\hline Aplicação científica & $\begin{array}{l}\text { Fornecer dados sobre a } \\
\text { situação de saúde }\end{array}$ & $\begin{array}{l}\text { Conhecer os processos } \\
\text { estruturais da saúde }\end{array}$ & $\begin{array}{l}\text { Compreender os processos } \\
\text { estruturais da saúde }\end{array}$ \\
\hline Adotado por quem & $\begin{array}{l}\text { Grupos e instituições, } \\
\text { acadêmicos e políticos } \\
\text { conservadores }\end{array}$ & $\begin{array}{l}\text { Grupos e instituições, } \\
\text { acadêmicos e políticos engajados }\end{array}$ & $\begin{array}{l}\text { Grupos e instituições, } \\
\text { acadêmicos e políticos } \\
\text { engajados, em diálogo com o } \\
\text { Estado e movimentos sociais }\end{array}$ \\
\hline $\begin{array}{l}\text { Intervenções } \\
\text { e aplicações } \\
\text { sociopolíticas }\end{array}$ & $\begin{array}{l}\text { Pontuais e desarticuladas, } \\
\text { marcadamente } \\
\text { sobre fatores de risco } \\
\text { Ações setoriais, principalmente } \\
\text { no setor saúde }\end{array}$ & $\begin{array}{l}\text { Processuais e integradas, } \\
\text { organização da sociedade, } \\
\text { do contexto social } \\
\text { Intersetorialidade formal }\end{array}$ & $\begin{array}{l}\text { Processuais e integradas, } \\
\text { organização da sociedade, do } \\
\text { contexto e relações sociais } \\
\text { Intersetorialidade crítica }\end{array}$ \\
\hline Intencionalidades & $\begin{array}{l}\text { Mitigação de situações de } \\
\text { saúde adversas } \\
\text { Controle de riscos individuais } \\
\text { Manutenção da ordem social }\end{array}$ & $\begin{array}{l}\text { Denúncia e eliminação } \\
\text { de situações adversas } \\
\text { Transformação da ordem social }\end{array}$ & $\begin{array}{l}\text { Denúncia e eliminação } \\
\text { de situações adversas } \\
\text { Transformação da ordem } \\
\text { social Relações sociais } \\
\text { emancipatórias }\end{array}$ \\
\hline
\end{tabular}

Fonte: Elaborado com base em Michelin (2015).

\section{Considerações finais}

A retomada e a sistematização da produção latino-americana na perspectiva dos contextos sociopolíticos de sua produção e do pensamento brasileiro não tem sido frequente na discussão sobre o tema. Se neste ensaio procuramos relacionar a produção sobre determinação e determinantes sociais da saúde na América Latina com o contexto dessa região ao longo do tempo, resta que teçamos algumas considerações sobre o momento histórico em que se escreve este texto. Laurell (2011) termina sua periodização da trajetória da medicina social/saúde coletiva latino-americana com o que denomina de 'o pós-liberalismo e as emergências progressistas'. É com inenarrável pesar que, 
nesse breve lapso de tempo, constatamos o feroz avanço do neoliberalismo não só no Brasil como também em outros países latino-americanos, através de governos que, eleitos democraticamente ou por meio de golpes, não hesitam em destituir direitos duramente conquistados e açoitam a saúde de seus povos, ao desmantelar os sistemas de saúde e promover reformas que não são outra coisa que a 'determinação social da doença'.

Fruto de esforços críticos e de resistência, refletimos sobre o papel que cabe à medicina social/saúde coletiva brasileira e latino-americana na atualidade. Primeiramente, é imprescindível ter-se um posicionamento claro e inequívoco de defesa intransigente de nossa (ainda que limitada) democracia. Há que se considerar a urgência de reiterar a aliança da academia com os movimentos sociais emancipadores e com os trabalhadores. Simultaneamente, encarregarse tanto da disputa dos espaços institucionais que vêm sendo cedidos aos que se alinham ao ideário neoliberal quanto da tarefa acadêmica, comprometida a denúncia da deterioração das condições de vida e de saúde das populações. Finalmente, as particulares adversidades que cada país latino-americano vem enfrentando não deixam de ser parte de um contexto geral, que se empenha em relegar a região a uma dócil posição periférica, razão pela qual a solidariedade latino-americana torna-se vital. Por esses motivos escrevemos porque, mesmo quando tudo parece uma migalha do que poderia ser, seguimos na certeza de que o novo sempre vem.

\section{Colaboradores}

Carolina Michelin Sanches de Oliveira Borghi foi responsável pela concepção, elaboração, redação e revisão final do texto. Rosely Magalhães de Oliveira colaborou na revisão crítica do texto. Gil Sevalho colaborou na revisão crítica e na redação final. 
Resumen La determinación social de la salud y los determinantes sociales de la salud se han presentado como sinónimos en un contexto de reanudación del tema. La concepción de determinación y determinantes, y la historicidad de estos modelos teóricos, transcienden el plano académico, al considerarse la particularidad que implica salud pública, salud colectiva y medicina social, en donde ciencia y política están estrechamente relacionadas. Al establecerse diferencias entre éstas denominaciones, en este ensayo se busca recuperar, en el plano teórico, el desarrollo de la determinación social de la salud, destacando su relación con el conocimiento producido en América Latina y su repercusión en Brasil, así como las influencias de los paradigmas científicos, epistemológicos, marcos teóricos y proyectos en disputa en este campo. Para abarcar dimensiones políticas y académicas que los modelos teóricos comportan, recurrimos a la ayuda de autores que transitan entre diferentes campos de conocimiento. Sin la pretensión de agotar todos los posibles puntos de vista que nuestra incursión proporciona, presentamos una síntesis de nuestra concepción del modelo teórico de determinantes sociales de la salud y principalmente de la determinación social de la misma, que proponemos desmembrar en dos categorías, determinación estructural y determinación estructural-relacional, de manera que al enfatizar epistemológicamente la complejidad, permita una mejor visión de los avances teóricos y metodológicos. Palabras clave determinación social de la salud; salud colectiva; epidemiología; epistemología.

\section{Notas}

${ }^{1}$ Fundação Oswaldo Cruz, Escola Nacional de Saúde Pública Sergio Arouca, Rio de Janeiro, RJ, Brasil.

<carolmichelin@yahoo.com.br>

Correspondência: Fundação Oswaldo Cruz, Escola Nacional de Saúde Pública Sergio Arouca, Rua Leopoldo Bulhões, 1.480, Manguinhos, CEP 21041-210, Rio de Janeiro, RJ, Brasil.

${ }^{2}$ Fundação Oswaldo Cruz, Escola Nacional de Saúde Pública Sergio Arouca, Departamento de Endemias Samuel Pessoa, Rio de Janeiro, RJ, Brasil.

<rosely@ensp.fiocruz.br>

${ }^{3}$ Fundação Oswaldo Cruz, Escola Nacional de Saúde Pública Sergio Arouca, Departamento de Endemias Samuel Pessoa, Rio de Janeiro, RJ, Brasil.

<gil@ensp.fiocruz.br>

\section{Referências}

ADORNO, Theodor W. O ensaio como forma. In: ADORNO, Theodor W. Notas de literatura I. São Paulo: Duas Cidades, 2003. p. 15-45.

ALMEIDA-FILHO, Naomar. Complejidad y transdisciplinariedad en el campo de la salud colectiva: evaluación de conceptos y aplica- ciones. Salud Colectiva, Buenos Aires, v. 2, n. 2, p. 123-146, 2006.

ALMEIDA-FILHO, Naomar. A problemática teórica da determinação social da saúde. In: NOGUEIRA, Roberto P. (org.). Determinação 
social da saúde e Reforma Sanitária. Rio de Janeiro: Cebes, 2010. p. 13-36.

ALMEIDA-FILHO, Naomar; PAIM, Jairnilson S. La crisis de la salud pública y el movimiento de la salud colectiva en Latinoamérica. Cuadernos Médicos Sociales, Rosario, v. 40, n. 75, p. 5-30, 1999.

ARREDONDO, Armando. Análisis y reflexión sobre modelos teóricos del proceso saludenfermedad. Cadernos de Saúde Pública, Rio de Janeiro, v. 8, n. 3, p. 254-261, 1992.

BARBOSA, Regina H. S. A 'teoria da práxis': retomando o referencial marxista para o enfrentamento do capitalismo no campo da saúde. Trabalho, Educação e Saúde, Rio de Janeiro, v. 8, n. 1, p. 9-26, 2010.

BOURDIEU, Pierre. O poder simbólico. Tradução de Fernando Tomaz. Rio de Janeiro: Bertrand Brasil, 1989.

BOURDIEU, Pierre. Os usos sociais da ciência: por uma sociologia clínica do campo científico. Tradução de Denice Barbara Catani. São Paulo: Ed. Unesp, 2003.

BREILH, Jaime. Derrota del conocimiento por la información: una reflexión necesaria para pensar en el desarrollo humano y la calidad de vida desde una perspectiva emancipatoria. Ciência \& Saúde Coletiva, Rio de Janeiro, v. 5, n. 1, p. 99-114, 2000.

BREILH, Jaime. Epidemiologia crítica: ciência emancipadora e interculturalidade. Rio de Janeiro: Editora Fiocruz, 2006.

BREILH, Jaime. Las tres ' $\mathrm{S}$ ' de la determinación de la vida: 10 tesis hacia una visión crítica de la determinación de la vida y de la salud. In: NOGUEIRA, Roberto P. (org.). Determinação social da saúde e Reforma Sanitária. Rio de Janeiro: Cebes, 2010. p. 87- 125.

BREILH, Jaime. Una perspectiva emancipadora de la investigación e incidencia basada en la determinación social de salud. México: Universidad Autónoma Metropolitana de Xochimilco y Asociación Latinoamericana de Medicina Social (Alames), 2011. Capítulo de libro.

BREILH, Jaime. La determinación social de la salud como herramienta hacia una nueva salud pública (salud colectiva). Revista Facultad Nacional de Salud Pública, Antioquia, n. 31, supl. 1, p. 13-27, 2013.

BREILH, Jaime; GRANDA, Edmundo. Saúde na sociedade. São Paulo: Cortez, 1989.

BUSS, Paulo M.; PELLEGRINI-FILHO, Alberto. A saúde e seus determinantes sociais. Physis: Revista de Saúde Coletiva, Rio de Janeiro, n. 17, v. 1, p. 77-93, 2007.

CASTELLANOS, Pedro L. Sobre o conceito de saúde-doença: descrição e explicação da situação de saúde. Boletín Epidemiológico OPS, v. 4, n. 10, p. $25-32,1990$

CASTELLANOS, Pedro L. Epidemiologia, saúde pública, situação de saúde e condições de vida: considerações conceituais. In: BARATA, Rita B. Condições de vida e situação de saúde. Rio de Janeiro: Abrasco, 1997. p. 31-75.

DESLANDES, Suely F.; IRIART, Jorge A. B. Usos teórico-metodológicos das pesquisas na área de ciências sociais e humanas em saúde. Cadernos de Saúde Pública, Rio de Janeiro, v. 12, n. 28, p. $2.380-2.386,2012$.

ESPINA-PRIETO, Mayra P. Complejidad, transdisciplina y metodología de la investigación social. Utopia y Práxis Latinoamericana, Maracaibo, v. 38, n. 12, p. 29-43, 2007.

FLEURY-TEIXEIRA, Paulo. Uma introdução conceitual à determinação social da saúde. Saúde em Debate, Rio de Janeiro, v. 33, n. 83, p. 380-387, 2009.

FLEURY-TEIXEIRA, Paulo; BRONZO, Carla. Determinação social da saúde e política. In: NOGUEIRA, Roberto P. (org.). Determinação social da saúde e Reforma Sanitária. Rio de Janeiro: Cebes, 2010. p. 37-59.

HARVEY, David. O neoliberalismo: história e implicações. São Paulo: Loyola, 2008. 
IRIART, Célia et al. Medicina social latinoamericana: aportes e desafíos. Revista Panamericana de Salud Pública [on line], v. 2, n. 12 , p. 128-136, 2002.

LAURELL, Asa C. Trayectoria y retos de la medicina social latinoamericana. Sítio virtual Alames, 2011. Disponível em: <https:// www.youtube.com/watch?v=urd068P2RxA $>$. Acesso em: 26 jun. 2017.

LÓPEZ-ARELLANO, Oliva. Determinación social de la salud: desafios y agendas posibles. Divulgação em Saúde para Debate, Rio de Janeiro, n. 49, p. 150-156, 2013.

LÓPEZ-ARELLANO, Oliva; ESCUDERO, José C.; CARMONA, Luz D. Los determinantes sociales de la salud: una perspectiva desde el Taller Latinoamericano de Determinantes Sociales de la Salud, Alames. Medicina Social [on line], v. 3, n. 4, p. 323-335, 2008. Disponível em:_<http://www.socialmedicine.info/index. php/medicinasocial/article/viewFile/260/538>. Acesso em: 26 jun. 2017.

LÓPEZ-ARELLANO, Oliva; SAINT MARTIN, Florencia P. Salud y sociedad: aportaciones del pensamiento latinoamericano. Medicina Social [on line], v. 1, n. 3, p. 82-102, 2006. Disponível em: <http://www.medicinasocial.info/index.php/medicinasocial/article/ view/41/109>. Acesso em: 26 jun. 2017.

MICHELIN, Carolina. Determinação social do processo saúde-doença: que vozes ecoam no Brasil? 2015. 129f. Dissertação (Mestrado em Saúde Pública) - Escola Nacional de Saúde Pública Sergio Arouca, Fundação Oswaldo Cruz, Rio de Janeiro, 2015.

MOISÉS, Massaud. Dicionário de termos literários. São Paulo: Cultrix, 2004.

MORIN, Edgar. Introdução ao pensamento complexo. 4. ed. Tradução de Eliane Lisboa. Porto Alegre: Sulina, 2011.

NOGUEIRA, Roberto P. Determinantes, determinação e determinismos sociais. Saúde em
Debate, Rio de Janeiro, v. 33 , n. 83 , p. $397-$ 406, 2009.

NOGUEIRA, Roberto P. A determinação objetal da doença. In: NOGUEIRA, Roberto P. (org.). Determinação social da saúde e Reforma Sanitária. Rio de Janeiro: Cebes, 2010. p. 135-150.

PAIM, Jairnilson S. Abordagens teórico-conceituais em estudos de condições de vida e saúde: notas para reflexão e ação. In: BARATA, Rita B. (org.). Condições de vida e situação de saúde. Rio de Janeiro: Abrasco, 1997. p. 7-30.

PEÑARANDA, Fernando; RENDÓN, Carlos. Determinismo-indeterminación y el debate de los determinantes-determinación social de la salud. Revista Facultad Nacional de Salud Pública, Antioquia, n. 31, supl. 1, p. 47-56, 2013.

RESTREPO-OCHOA, Diego A. Determinismo/ indeterminismo y determinación: implicaciones para el campo de la salud pública. Revista Facultad Nacional de Salud Pública, Antioquia, n. 31, supl. 1, p. 42-46, 2013.

SABROZA, Paulo C. Concepções sobre saúde e doença. In: SANTOS, Elizabeth M.; NATAL, Sônia (orgs.). Dimensão técnico-operacional: unidade didático-pedagógica. Rio de Janeiro: Abrasco, 2005. p. 350-369.

SAMAJA, Juan. Epistemología y epidemiologia. In: ALMEIDA-FILHO, Naomar et al. (orgs.). Teoria epidemiológica hoje: fundamentos, interfaces, tendências. Rio de Janeiro: Editora Fiocruz, 1998. p. 23-36.

SAMAJA, Juan. A reprodução social e a saúde: elementos teóricos e metodológicos sobre a questão das 'relações' entre saúde e condições de vida. Salvador: Casa da Qualidade Editora, 2000.

SANTOS, Boaventura S. Um discurso sobre as ciências. 7. ed. São Paulo: Cortez, 2006.

SANTOS, Boaventura S. Renovar a teoria crítica e reinventar a emancipação social. São Paulo: Boitempo, 2007. 
SANTOS, Boaventura S.; MENESES, Maria P. Introdução. In: SANTOS, Boaventura S.; MENESES, Maria P. (orgs.). Epistemologias do Sul. São Paulo: Cortez, 2010. p. 15-27.

SOLAR, Orielle; IRWIN, Alec. Rumo a um modelo conceitual para análise e ação sobre os determinantes sociais de saúde. Genebra: Organização Mundial da Saúde, 2005. Disponível em: <http://www.bvsde.paho.org/ bvsacd/cd57/comissao.pdf>. Acesso em: 26 jun. 2017.
WAITZKIN, Howard et al. Social medicine in Latin America: productivity and dangers facing the major national groups. The Lancet, v. 358, n. 9.278, p. $315-323,2001$.

Recebido em 17/07/2017

Aprovado em 21/11/2017 